\title{
THE TEA WORKERS
}

\author{
By \\ Prerana Das
}

B.A, Media Studies and English, University of Toronto, 2013.

\author{
A Major Research Paper \\ presented to Ryerson University \\ in partial fulfillment of the \\ requirements for the degree of \\ Master of Fine Arts \\ in the program of \\ Documentary Media
}

Toronto, Ontario, Canada, 2019

(C) Prerana Das, 2019 


\section{Author's Declaration}

I hereby declare that I am the sole author of this MRP. This is a true copy of the MRP, including any required final revisions.

I authorize Ryerson University to lend this MRP to other institutions or individuals for the purpose of scholarly research.

I further authorize Ryerson University to reproduce this MRP by photocopying or by other means, in total or in part, at the request of other institutions or individuals for the purpose of scholarly research.

I understand that my MRP may be made electronically available to the public. 


\author{
Abstract \\ The Tea Workers \\ Prerana Das \\ MFA in Documentary Media, 2019 \\ Ryerson University
}

The region of Darjeeling has been a backdrop for political conflict since its colonization by the British in the 1800s. In the aftermath of the politically-motivated 104-day long citywide shutdown in the summer of 2017, Darjeeling's tea industry took a significant hit. The forced closure of the plantations meant that workers were unable to earn wages, in spite of often being at the frontlines of the Gorkhaland movement protests. This paper contextualizes the research that went into the short film The Tea Workers. In particular, it explores the complexity of the female experience of labour on and around tea plantations, as well as the ways in which labour and gender hierarchies intersect to uniquely affect women labourers in the politicized landscape of tea production. 


\section{Acknowledgements}

I would like to firstly thank the women who work in Darjeeling's tea industry and were willing to share their thoughts with me. This film would clearly not have been possible without all of their valuable input.

Secondly, I would like to thank Dr. Sarah Besky of Brown University and Dr. Jayeeta Sharma of the University of Toronto, both of whom met with me during my research phase and offered valuable advice on best processes for approaching the subject matter. I appreciate them taking the time to speak to me about their own research on Darjeeling's tea industry.

Thirdly, my supervisors Katy McCormick and Brett Story have provided guidance throughout the process of pre-production and writing. Outside of Ryerson University, I would also like to thank Nuzhat Abbas and Ingrid Hamilton, who have both given me valuable input at various points throughout my editing process 


\section{TABLE OF CONTENTS}

List of Figures vi

Table of Contents

1. Introduction

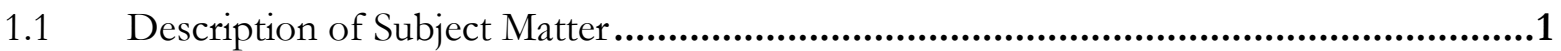

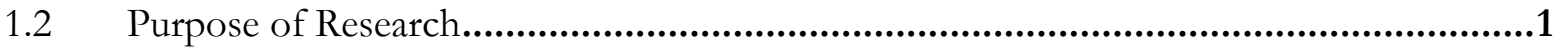

2. Historical and Social Context

2.1 The Exoticization of Darjeeling's Tea, Landscape, and Women................................. 3

2.2 Labour Justice, Gender Disparities, and Double Exploitation.................................... 5

2.3 Effects of Gorkhaland Movement on Plantations ....................................................6

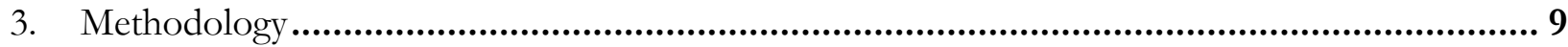

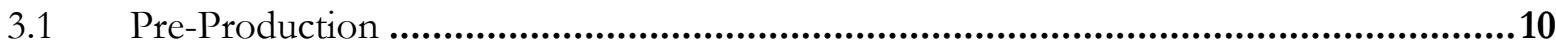

Interview Subjects and Locations ................................................................. 11

3.3 Ethical and Technical Challenges of Distance ....................................................17

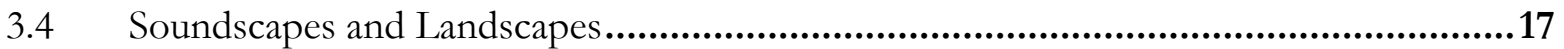

3.5 Portraying a Growing Sense of Discontent ....................................................22

4. Documentary Relevance ........................................................................................24

4.1 Exoticization and the Ethnographic Gaze .......................................................26

4.2 Positionality within the Community .....................................................................29

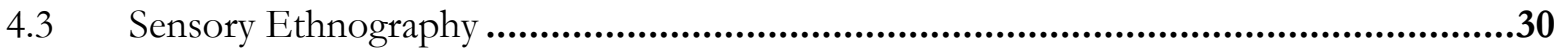

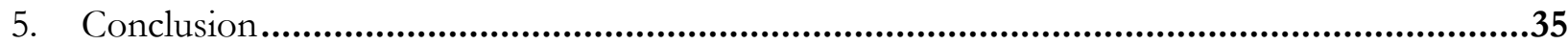

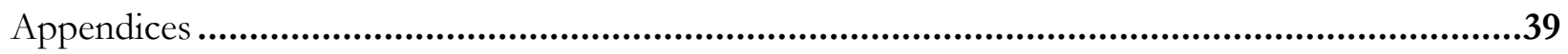

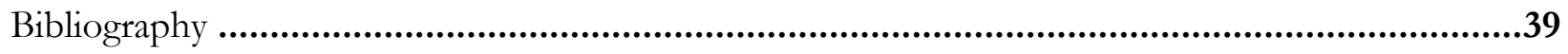




\section{List of Figures}

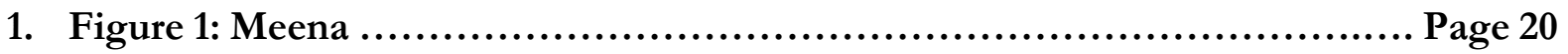

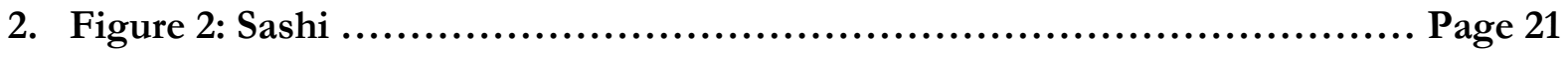

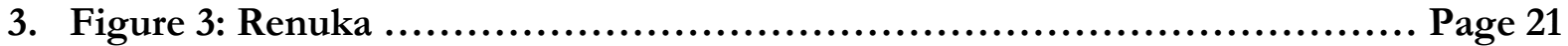

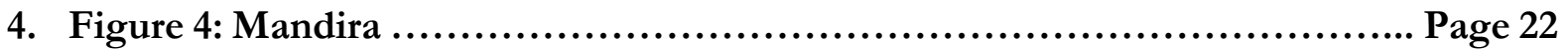

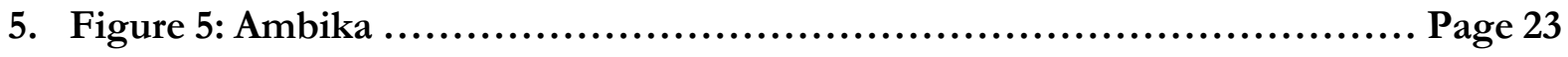

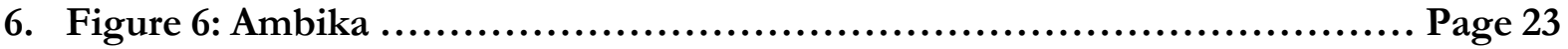




\subsection{Description of Subject Matter}

The myth of Darjeeling tea involves several familiar motifs: fragrant and colourful leaves; Himalayan mountains and lush green hills; and beautiful women in vibrant coloured clothing plucking tea. This myth has permeated popular culture over the decades and these images continue to be disseminated in modern day marketing materials for tea.

The plantation itself has been a backdrop for political upheavals in Darjeeling over several decades, and has been affected both physically and economically. The 104-day long strike in the summer of 2017 prompted a forced shutdown of the plantations and a subsequent sharp decline in tea exports. This situation also meant that workers were unable to earn wages during the strike.

This film and research paper explore the ways in which labour and gender hierarchies intersect to uniquely affect women in the currently unstable, changing landscape of tea production. The Tea Workers features a collection of personal stories and reflections which speak to the nuances of everyday life in Darjeeling one year after the strike. These stories also draw attention to the complexity of the female experience of labour on and around tea plantations. They aim to challenge the exoticization of Darjeeling's tea, landscape, and women inside and outside of the plantation.

\subsection{Purpose of Research}

The ways in which people in the Western world consume tea is influenced by a centurieslong history of colonization. After the Anglo-Gorkha War of 1816, the British took control of one third of Nepal's territories and added them to the district of Darjeeling. Tea seeds were planted 
throughout the hills, and more plantations were created as the industry grew. To meet the demand from the west, thousands of labourers were brought over from Nepal. This migration heightened ethnic tensions and Darjeeling remained a backdrop for political conflict throughout its history.

The Tea Workers and this supporting paper aim to question the long-ranging impacts of this colonization on the landscape, tea industry, and labourers. It aims to question the sources of the stereotypes associated with Darjeeling tea through a deeper and more meaningful understanding of the production process. Finally, it aims to question the inherent politics behind the tea and landscape, and whether these elements can exist outside of the politics of the Gorkhaland separatist movement. 


\subsection{The Exoticization of Darjeeling's Tea, Landscape, and Women}

Darjeeling tea carries with it a certain level of market distinction. Particularly in the western world, it has become synonymous with "expensive" and "refined." Marketing materials throughout the years have contained images of Nepali women and rolling hills. The exoticization of Darjeeling's tea as expensive and refined provides a stark contrast to the working and living conditions of the tea labourers who actually work in the gardens. Scholar Sarah Besky writes that:

The term landscape has two important meanings. In one sense, a landscape is a static, looked-upon, talked-about material world. In a second sense, a landscape is a moving, dwelt-in world. For anthropologists, ideas about and experiences of landscapes inform one another to produce "place." Making place means making political, economic, or social use of the landscape's past, or perhaps even inventing or revising it. ${ }^{2}$

Using this anthropological perspective as a starting point, I aim to examine Darjeeling's landscape through a critical and decolonial perspective. ${ }^{3}$ The landscape has been the backdrop of war and political violence throughout history. The British shaped the borders of the region during their colonization of India, and these became the regional boundaries over which Gorkhaland activists have been fighting for decades. Besky explains that "[t]o Darjeeling residents, [the] history of colonization has become visible in Darjeeling's landscape of imperial ruins, the social and material remains that Darjeeling residents were, in Stoler's words, 'left with' after the colonial period." ${ }^{\text {The }}$ residents themselves grapple with the remnants of Darjeeling's colonial history.

\footnotetext{
${ }^{1}$ Sarah Besky, The Darjeeling Distinction: Labor and Justice on Fair-Trade Plantations in India. Berkeley: University of California Press, 2014, 40 . 
On top of this, the Partition of India in 1947 prompted parts of the Bengali population to flee to Darjeeling as refugees. From the years 1996 and 2006, the Maoist Civil War was fought between the Maoist Party of Nepal and the Nepalese government. This decade of war resulted in thousands of deaths and even more migrations and displacements. ${ }^{5}$ Because of such continuous political turmoil, the history of Darjeeling as a region is closely intertwined with the histories of Nepal, Bhutan, Sikkim, and Bangladesh. The town became a hub for migrants, and the landscape became a backdrop for lines of movement often spanning generations.

The myth of Darjeeling tea is also closely tied with the exoticization of its women. Marketing materials for tea often feature images of smiling, beautiful female tea pluckers; this image has become synonymous with the market distinction associated with Darjeeling tea. ${ }^{6}$ Furthermore, the relationship between labour workers and the postcolonial landscape is one which has evolved as planters work to change the conditions under which future generations of workers and inhabitants inherit the landscape. ${ }^{7}$ The plantation also carries a paradox; on one hand, it represents a space of nurture through refugees' and immigrants' developing affinity towards the physical land. ${ }^{8}$ Due to the delicacy of the plant, the field requires a caring labour force, and it therefore becomes essential for plantation workers to have an emotional investment in their work. On the other hand, there is a noticeable chain of hierarchy between labourers and individuals who work on the business side of corporations, buying and selling tea from these estates. Women are usually seen working as labourers, but rarely within trade unions or the administrative side.

\footnotetext{
${ }^{5}$ Nandini Bhattacharyya-Panda, Culture, Heritage, and Identity: The Lepcha and Mangar Communities of Sikkim and Darjeeling. Kolkata: Maulana Abul Kalam Azad Institute of Asian Studies in Association with KW Publishers, New Delhi, 2015.

${ }^{6}$ Besky, The Darjeeling Distinction. 40.

7 Ibid 40.

$8 \operatorname{Ibid} 40$.
} 


\subsection{Labour Justice, Gender Disparities, and Double Exploitation}

The unfair treatment of labourers on tea plantations has been an ongoing issue for activists in and around Darjeeling. The minimum daily wage for workers, which was recently raised to Rs.172, is not a proper living wage. ${ }^{9}$ For comparison, Rs. 172 is roughly equal to $\$ 3.21$ Canadian dollars. Several plantations offer part of their workers' wages "in kind"; this may include medical benefits, fuel, and part of their food and grains provided at reduced rates. ${ }^{10}$ However, there are several issues with these in kind payments. In $A$ Time for Tea, Piya Chatterjee writes:

The feminization of labor and commodity is produced through a culture of patronage in which the personhood of the planter-manager-sahib stands tall. The construction of a benevolent father figure within the organizing rubric of the laboring family draws the basic parameters of the patronage system. It blunts the coercive practices of the work regimes and creates an aura of legitimation. It cements a "moral economy" through which the plantocracy and working class consent to, legitimate, and resist the terms of wage labour. ${ }^{11}$

In this way, the patriarchy upholds the same labour injustices that have been going on for

decades within the plantations. This aforementioned father figure becomes the one who has control over the livelihoods of the working class.

When examining the chain of labour that exists within the system of the plantation, certain gender disparities come to the forefront. On one hand, the majority of labourers working in the gardens are women. These are the people who pluck, weed, and prune the actual leaves, which often requires a discerning eye and technique. On the other hand, those working on the administrative, corporate, and trade sides of the industry are predominantly men.

\footnotetext{
9 “The Minimum Wage Act and The Tea Garden Workers.” The Darjeeling Chronicle. August 09, 2018. http://thedarjeelingchronicle.com/the-minimum-wage-act-and-the-tea-garden-workers/.

10 Sharit K Bhowmik, "Tea Plantation Wage Agreement: Workers' Interests Sacrificed." Economic and Political Weekly 29, no. 41 (1994): 2645-647. http://www.jstor.org/stable/4401878.

11 Piya Chatterjee, A Time for Tea: Women, Labor, and Postcolonial Politics on an Indian Plantation. Durham (N.C.): Duke University Press, 2005,6 .
} 
Along with the gender disparities that exist in the workplace, there is also a sense of double exploitation when it comes to women in Darjeeling. On top of insufficient wages and humid, physically draining and generally undesirable working conditions, women are also expected to fulfill domestic responsibilities. These women take their children to school, cook meals for their husbands and children, and take care of their households. This results in women being doubly exploited. As Chatterjee continues to explain:

The planter sits astride a pyramid whose base is field labor ... constituted by women who dominate the necessary site of the plantation's political and cultural economy.

Simultaneously fetishized (in the commodity picturesque) and pragmatically devalued (in lower wages) women's fieldwork - tea plucking - creates the outer perimeter of the plantation field ... Because overseers are often high-status men in the plantation villages and 'labor lines,' the patriarchal and paternal disciplining within plucking regimes is doublepronged ... the overlordship of the burra sabib [a vernacular term meaning master or gentleman]... resonates within the immediacy of community-rooted and customary norms of village patriarchy. ${ }^{12}$

In this way, women working within the plantation exist within a world of multi-layered patriarchies, and the communities from which they come uphold these patriarchal values. None of these facts work in their favour when it comes to labour justice and fair wages.

\subsection{Effects of Gorkhaland Movement on Plantations}

On the $16^{\text {th }}$ of May 2017, the West Bengal government announced that Bengali should be a compulsory language taught in all schools across the state. This announcement prompted an initial series of protests by supporters of the Gorkha Janamukti Morcha party, which was formed in 2007 with the main purpose of creating a separate self-administering state out of districts currently under

\footnotetext{
12 Ibid, 6.
} 
the governance of West Bengal. ${ }^{13}$ After the initially peaceful protests began to intensify, the Government of West Bengal clarified that Bengali would only be an optional subject in schools in the hills rather than a mandatory one. However, in spite of this clarification, leadership within the GJM party continued to intensify protests, reviving a decades-long struggle over the demand for the separate statehood of Gorkhaland. Amidst increasingly violent clashes between the West Bengal government and the GJM, the latter called for an indefinite shutdown of the region. ${ }^{14}$

The shutdown of the Darjeeling hills caused the tea industry to suffer a major economic blow. Garden workers not going to work meant that tea was not being plucked, sold, or exported. In addition to this, the livelihood of over two hundred thousand workers was put under threat throughout this time. ${ }^{15}$

The strikes also prompted several instances of arson; government properties, vehicles, the Darjeeling Himalayan Railway, and multiple schools were burned or attempted to be burned. Throughout the months, there were several rounds of talks and negotiations between the government and the GJM; however, none of these initially resulted in a satisfactory conclusion acceptable to both parties. On the $27^{\text {th }}$ of September, one hundred and four days after the beginning of the shutdown, the GJM's new chairperson Binay Tamang called off the strike.

Throughout the agitations, women were at the forefront of protests. The Gorkha Janmukti Nari Morcha is the women's wing of the GJM party and largely consists of housewives who favour peaceful demonstrations and rallying. During the agitations, Prabitha Rai, a senior women's wing leader, explained that "This [was] an emotional agitation and a people's movement."”

\footnotetext{
13 Sumanta Ray Chaudhuri, "Demand for Gorkhaland: How Bengali Language Derailed Peace in Darjeeling." Https://www.hindustantimes.com/. June 15, 2017. https://www.hindustantimes.com/india-news/demand-for-gorkhaland-thedarjeeling-crisis-began-with-the-bengal-govt-announcement/story-S7VdgGSabmfxvLKoXc76mO.html.

14 Ibid.

15 Ibid.

16 Probir Pramanik, "Meet the 'Gandhian' Women Leading the Gorkhaland Stir in Darjeeling." Https://www.hindustantimes.com/. June 20, 2017. https://www.hindustantimes.com/india-news/meet-the-gandhian-women-leading-the-gorkhaland-stir-indarjeeling/story-raRs8Mvc4H2T7dqcEzmZnO.html.
} 
Following the end of the shutdown, there was not much change to the way that tea labourers were treated. On August $6^{\text {th }}, 2018$, the minimum daily wage was raised only Rs.22, from the already insufficient Rs.150 to Rs.172. ${ }^{17}$ In spite of several attempts at negotiations throughout the shutdown, it seems that no one prioritizes the interest of tea labourers - neither the GJM party, nor the West Bengal government. A lot of people at the forefront of the protests were also members of the working class; however, they benefited the least, if at all, from the Gorkhaland-related agitations.

17 “The Minimum Wage Act and The Tea Garden Workers.” The Darjeeling Chronicle. August 09, 2018. http:/ / thedarjeelingchronicle.com/the-minimum-wage-act-and-the-tea-garden-workers/. 


\section{Methodology}

The Tea Workers intertwines character portraits, landscapes, and soundscapes. Each subject has his or her own self-contained vignette, which showcases his or her process of work while engaging in a conversation. James P. Spradley, a former Professor of Anthropology, writes about ethnographic approaches to interviewing subjects, including linguistic and field work techniques, taxonomies of ethnographic questions, componential analyses, and analyses of cultural themes. ${ }^{18}$ Spradley's suggestions for researching specific cultural conventions and establishing a reciprocal relationship with subjects are particularly relevant to this project, and I aimed to prioritize an understanding of social intricacies throughout my fieldwork and interviews. The Tea Workers draws inspiration from films such as The Gleaners and I by Agnès Varda, in which she records conversations with subjects while situating them in their places of work. By taking this approach, I sought to draw connections between individuals and their environments to explore the ways in which the landscape influences their work and identities.

John Collier Jr. writes about the camera as a research tool and the role of photography and film as research methods in the field of visual anthropology. He breaks down a series of manageable dimensions of contemporary anthropological methodology which can be used to augment a visual approach to anthropology. In particular, he focuses on the use of photography and other media as field research, as well as the camera's role as a potential research tool. Collier deconstructs the complex relationship between the observer behind the camera and the subject in front of it. When shooting The Tea Workers, Collier and contemporary researchers' writing on visual anthropology inform and inspire my approach to interviewing individuals from a community in which I am an outsider.

18 James P Spradley, The Ethnographic Interview. Australia: Wadsworth Group/Thomson Learning, 1979, 2. 


\subsection{Pre-Production}

When I decided to approach the subject of Darjeeling's tea gardens, I knew my status as an outsider and subsequent lack of connections in the town might pose as issue with access, along with ethical questions surrounding my own voice as a filmmaker, which will be discussed later on in this paper. I reached out by email to various organizations connected to the tea industry months before shooting in June. Some of my efforts received positive but vague responses, and some received none. Because Darjeeling itself is not a metropolitan city, most connections are understandably made on the ground. This meant that I would have to find interview subjects a different way.

Trying to make these connections through the Internet revealed a lot about how people in Darjeeling connect with one another generally. The fact that it was difficult to make these connections remotely from Toronto shows that relationships are formed on and around the landscape itself. It also revealed the extent to which I was an outsider, especially before shooting in Darjeeling. During the shutdown of 2017, inhabitants of the region had no access to the Internet and electricity; however, society kept functioning because people adapted to these conditions and adopted alternative systems to survive, such as bartering with their neighbours. ${ }^{19}$

During a master's project development class, my classmate Daniel Clarkson Fisher mentioned that he knew of someone who I might be able to hire as a translator. I reached out to Kabir Pradhan and he was thankfully available during the time I intended to shoot, and interested in being my translator throughout the project. This simplified matters greatly, as Kabir ended up doing a lot of groundwork on my behalf in and around Darjeeling. Because he is a native Nepali speaker, he was able to gain access to plantations and organizations during the pre-production process and throughout the time we were shooting.

${ }_{19}$ India Darjeeling Strike Ends after 100 Days - BBC News. www.bbc.com/news/world-asia-india-41410887. 
Kabir's own family has a deep connection with the tea industry; his uncle owns a plantation in the region of Siliguri near Darjeeling, and several of his family members work in the industry. While a male translator was not my intended choice because the gender dynamic added to the already complex power structure behind the interviews - which I will discuss in the following subsection - his connection was ultimately another example of how intertwined tea is in the lives and family histories of local inhabitants. Darjeeling's cultural and economic landscape revolve around tea production to this day.

\subsection{Interview Subjects and Locations}

Going into this project, I knew I wanted to prioritize female perspectives and voices. While I interviewed some men who work in the tea industry, I ultimately chose not to include these subjects in the final film, opting to use them as research instead. I spoke to a number of different women in Makaibari and Rangaroon plantations - including factory workers, garden workers, and office workers - hoping to cover a range of perspectives from each part of the tea production process.

I also aimed to include a separate perspective which carried a different weight - while the workers' testimonies hold authority because of their firsthand experience in the gardens, I wanted to complement this with a tea activist's perspective. I separately interviewed a male and female activist who both work for labour justice in the plantations. While both provided valuable stories and research, I ultimately decided to include Ambika because of my aforementioned decision to prioritize female voices. She is a graduate student at the University of North Bengal, studying plantations for her thesis work. Because she is learning about the social justice issues surrounding 
Darjeeling's landscape herself as she continues her education and activism, I felt her positionality was particularly meaningful to the narrative.

My primary goal when recording interviews was to capture a sense of place in relation to individual and collective experiences. It was integral for me to situate my subjects within their places of work, or in a setting with which they were completely familiar. For Meena, Renuka, and Sashi, this was their place of work (the office, the factory and the garden, respectively); for Mandira and Manisha, this was their lunch area; and for Ambika, this was her university campus.

Before shooting this film, my background was primarily in photography. Drawing from this experience, I approached the interviews as individual portraits in terms of framing and composition. The viewer is meant to focus on the women's atmosphere and presence as much as on their words. I aimed to capture the women in a natural and comfortable state while also highlighting the importance of their individual voices. In The Burden of Representation, John Tagg writes:

[T] he change from a profile representation to a full face ... summon[s] up a complex historical iconography and elaborate codes of pose and posture readily understood within the societies in which such portrait images had currency. The head-on stare, so characteristic of simple portrait photography, was a pose which would have been read in contrast to the cultivated asymmetries of aristocratic posture. ... Rigid frontality signified the bluntness and 'naturalness' of a culturally unsophisticated class. ${ }^{20}$

Taking these notions into consideration, I aimed to include a few different angles for each subject while interviewing them. In each case, I wanted to portray the women's broad understanding of their own spaces of work. For example, during Meena's interview, the camera looks slightly upwards at her to show that the viewer is in a position to learn from her experience of how Makaibari plantation operates (Figure 1). In the background, the greenery of the fields is visible through the windows, while Makaibari's office and informational board are visible behind Meena in

\footnotetext{
${ }^{20}$ John Tagg, The Burden of Representation: Essays on Photographies and Histories. University of Minnesota Press, $1993,36$.
} 
the foreground. This ties into the fact that she speaks from years of experience in the fields as well as in the office more recently.

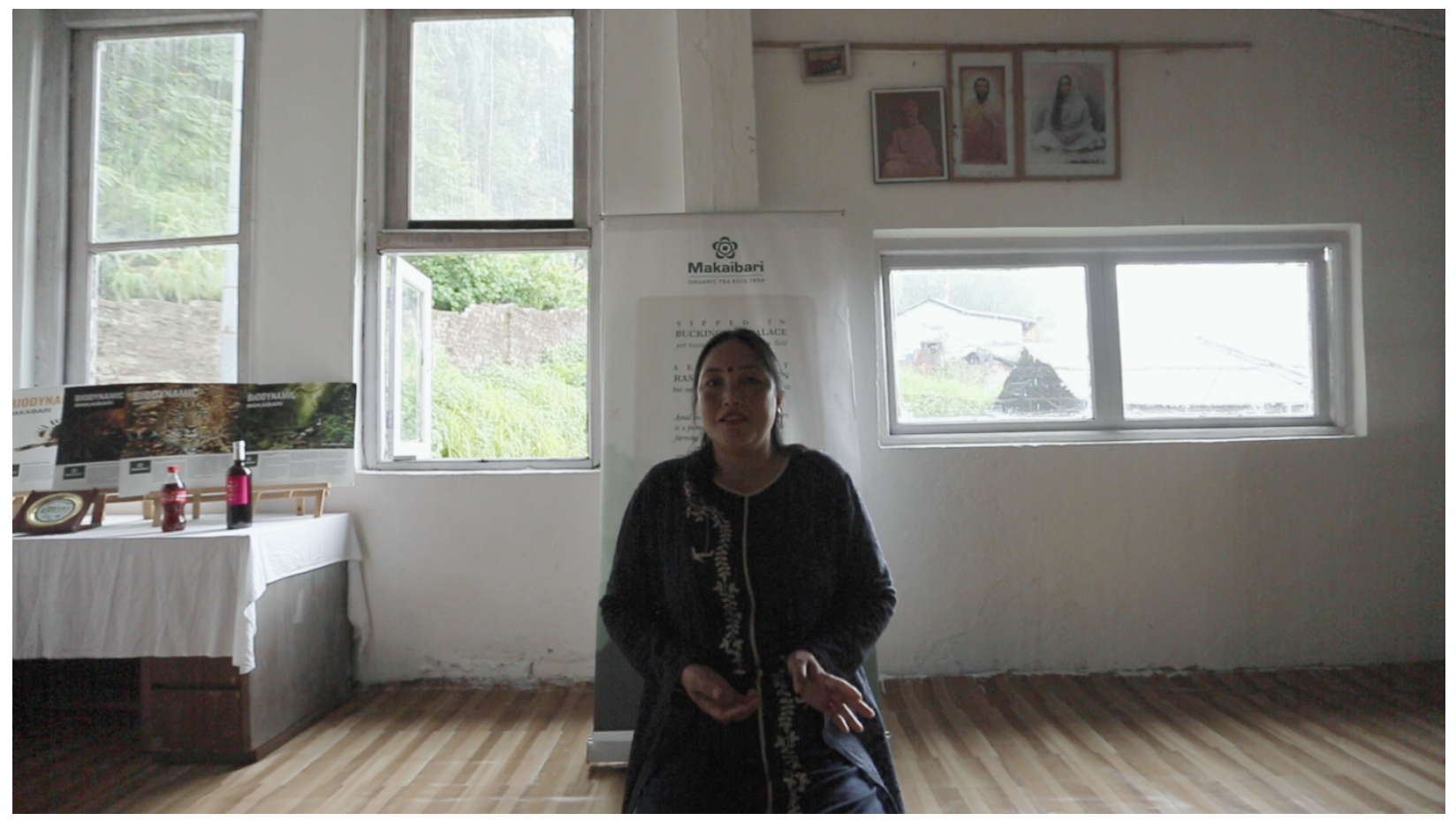

Figure 1: Meena

Similarly, when filming Sashi's interview, I wanted to capture her full body in her work uniform, centered within the loud chaos of the factory setting. She exists at ease in the environment because of her years of experience (Figure 2). In Renuka's case, she is shown to stand out and yet complement the greenery behind her. Looking at her through a lens of portraiture, I wanted to capture my sense of admiration for her by breaking away from the traditional visual of a talking head (Figure 3). 


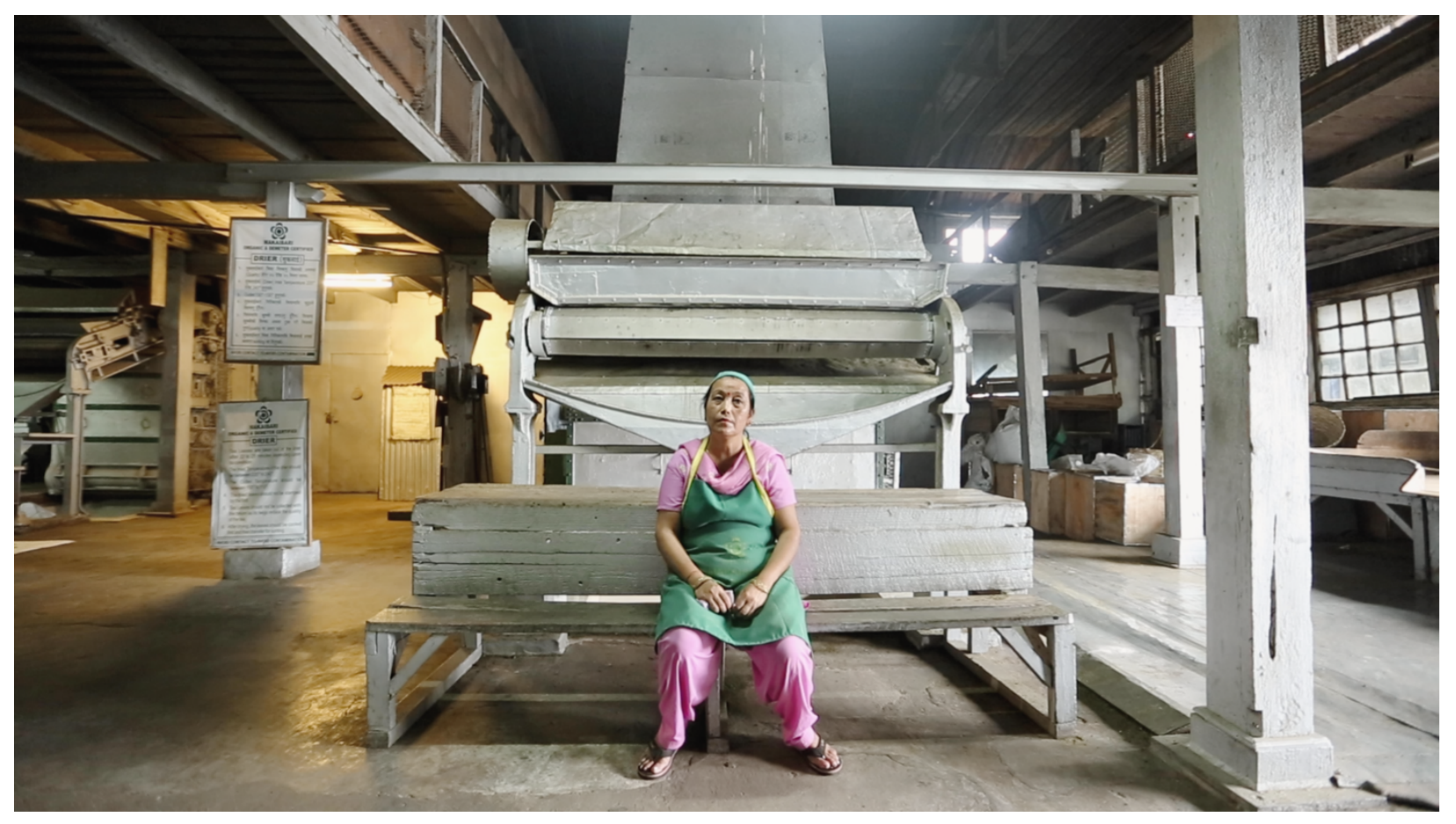

Figure 2: Sashi

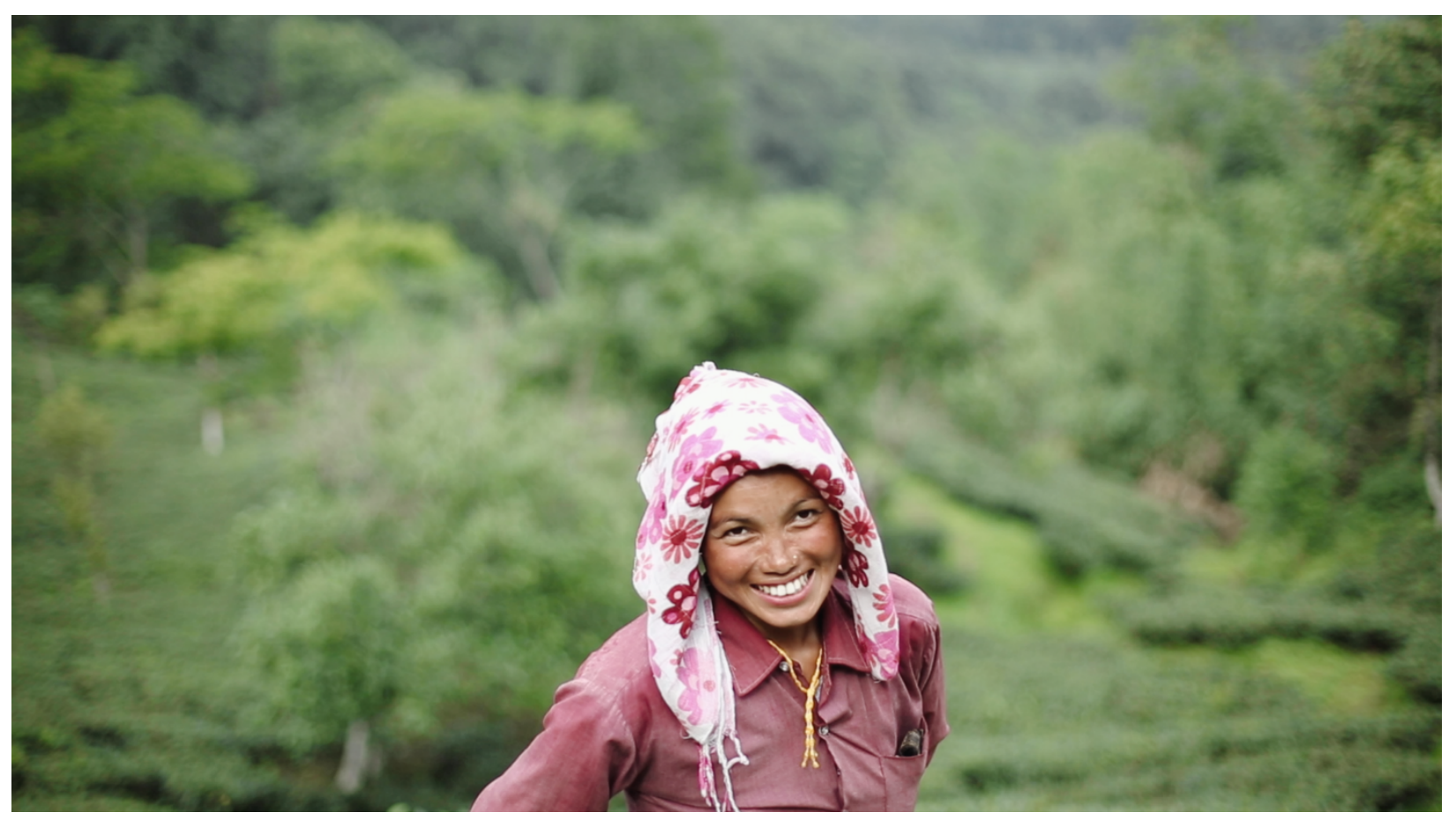

Figure 3: Renuka 
During Mandira's interview, she opened up freely while surrounded by her friends and coworkers in their lunch area. Within the frame, she sits beside a male co-worker who looks over in affirmation or acknowledgement once in a while but never speaks (Figure 4). At one point during the interview, Mandira's female colleague chimes into the conversation, adding her own thoughts about wages, labour, and the next generation, all while remaining off-screen. Instead of seeing this new speaker, the viewer witnesses Mandira's and her male co-worker's reactions to her thoughts. My reason for keeping this new speaker off-screen was to allow her to speak freely and anonymously; as a result, she offers up some harsh realities about the tea industry that some people were more reluctant to address explicitly on camera.

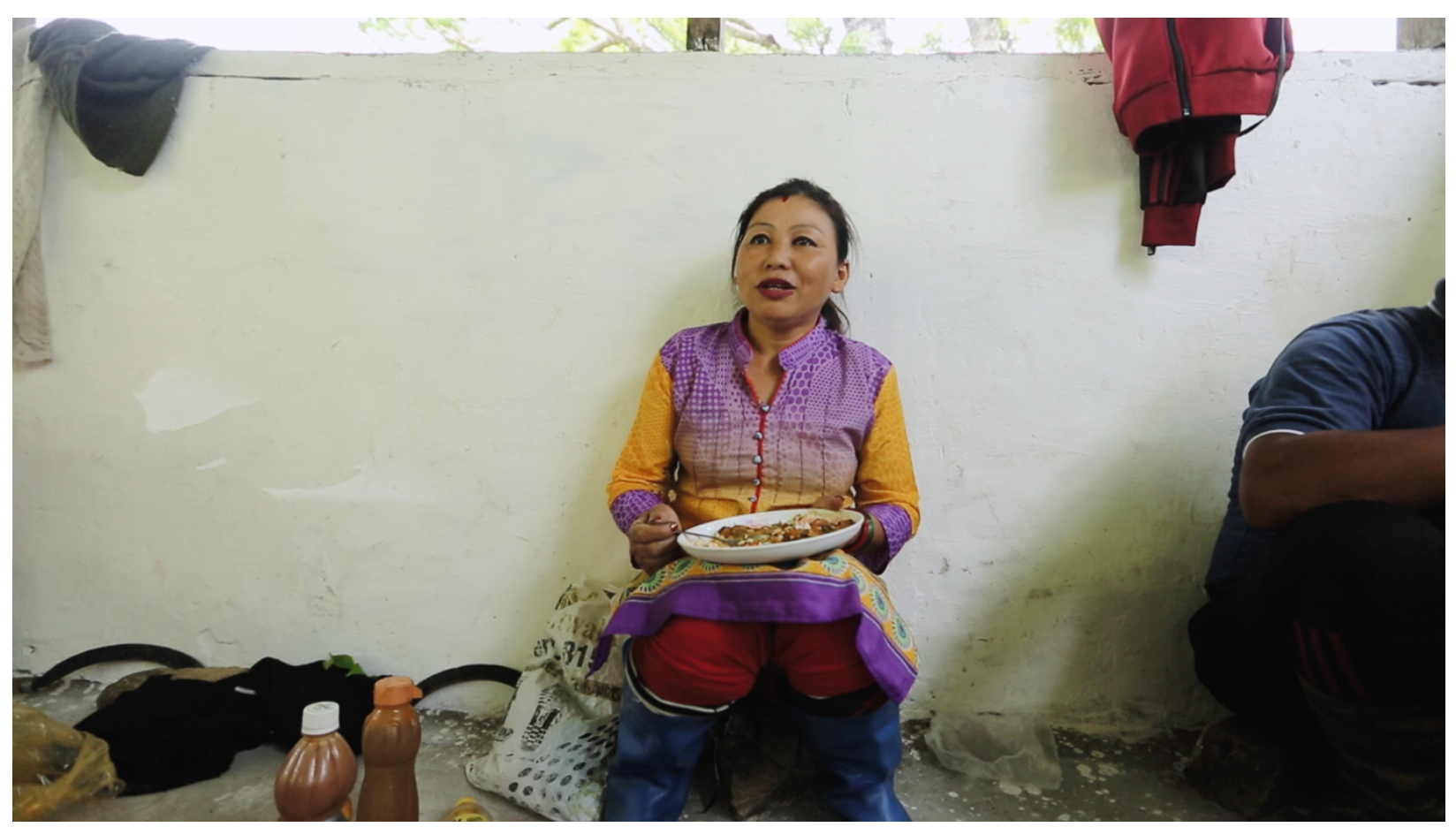

Figure 4: Mandira

When writing about the emergence of the talking head in NFB documentaries, Michael Brendan Baker explains that "the talking head was initially an ordering device functioning in such a manner that the direct address of voiceover narration could be excluded by filmmakers without fear 
of the film's rhetorical aims being encumbered. 'Historical judgment is replaced by personal testimony,' according to [Bill] Nichols, as the 'omniscient deity is concealed in the form of the obedient mouthpiece." ${ }^{21,22}$ Ambika was the one subject that I shot in a more visually traditional talking head style; however, this angle was complemented by several other angles of her shot wide, medium, and close-up (Figures 5, 6). I combined these angles when editing because Ambika's testimony is a personal one because she grew up in Darjeeling, as well as a voice of authority because she has studied the industry.
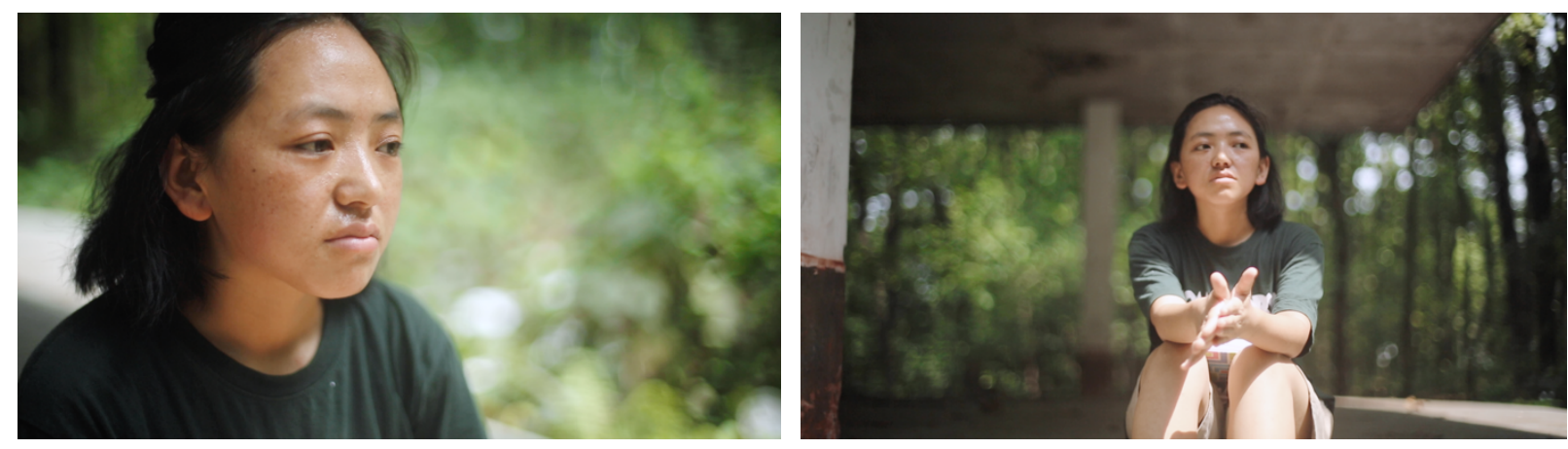

Figures 5, 6: Ambika

All of my subjects seemed to have a deep, multi-generational connection to Darjeeling. For this reason, it was essential to speak to them in these spaces of familiarity and comfort. I tried to make the most of each space in spite of the loud atmospheric noises. This proved to be particularly challenging in the factory and the lunch area, both of which had loud background noises. I ultimately chose to retain these noises for the sake of authenticity; the reality is that these women have bustling and loud work environments, so it felt appropriate to include that.

21 Bill Nichols, "The Voice of Documentary," Film Quarterly XXXVI, no. 3 (1983): 54, 58.

22 Michael Brendan Baker, "DRESDEN STORY AND THE EMERGENCE OF THE TALKING HEAD IN THE NFB DOCUMENTARY," Canadian Journal of Film Studies 17, no. 2 (Autumn, 2008): 1-17. 


\subsection{Ethical and Technical Challenges of Distance}

Shooting alone, with a translator, and as an outsider provided a huge learning experience. I found that because I was unable to communicate directly with the subjects who spoke Nepali only, I was not as in control of the situation as my translator. For this reason, I found myself having to adapt to situations based on where the conversation was taken by the translator, and learning to find meaning in the scenes in which we would end up. Because he spoke the language and grew up surrounded by the same social norms as the local inhabitants, Kabir was able to form relationships and gain a positive rapport with people much more effectively than I would have. However, this means that in spite of the fact that I was an outsider interrogating the roles of these women, he became the face of these interviews and of this project in a way, enabling me to erase my presence from the film almost completely. My inclination to remove myself came from the desire to amplify other voices; however, negotiating my own relationship with them carried a complexity which I ultimately did not address in the film.

Furthermore, I learned that Kabir had a tendency to immediately ask follow up questions as was the natural flow of conversation, in spite of my multiple requests to wait a few seconds after the subject answers. Interrupting Kabir would also break the flow and I had to resist doing this; however, this caused issues in editing and led to the inclusion of jump cuts in the final film. All of this means that he had a great influence on this project and the content of the interviews, even though I had prepared the questions, informed Kabir of my research, and was always present.

Nevertheless, it is highly unlikely that I would have been able to gain access to the plantations at all without Kabir's connections and persistence on the ground while I was in Toronto. Along with gaining initial access, a lot of the women opened up after conversing with Kabir and after he explained the nature of the documentary to them. I was faced with a moderate amount of 
resistance from people when it came to discussing politics on camera. The term "documentary" has negative connotations in the plantations because we were informed that a BBC documentary crew once did an exposé-style documentary on the tea industry, ${ }^{23}$ but did not come back to benefit the workers in any way after these interviews; rather, the plantation owners reacted punitively towards the workers who spoke out against them. For this reason, the workers' resistance to speak on camera for another documentary project was understandable. Upon realizing how some women felt about being recorded while talking about certain topics, I had to respect that. Instead of talking directly about politics, I would focus more on personal reflections, noticing that the women would inevitably open up without making any direct accusations. Since this is what they were comfortable sharing, it was enough for my purposes.

This process demonstrated that being able to understand my subjects and respond to their answers empathetically in real time is important to me. Furthermore, the process of captioning was tedious because not only was I correcting the grammar and structure of the English translations, but I was also matching the translations to the footage with a limited understanding of the cadence of the language. Along with the technical roadblocks this raised, it also prompted me to further consider my own voice and positionality. In editing these captions, I was altering and revising the words of these women as well as my translator, which raised more ethical questions about my distance as an outsider, because it removed me a step further from the direct words of the subjects.

During the editing process, I started to notice certain gaps and missing imagery in my footage. When attempting to create the atmosphere, I realized it was important to portray certain locations and parts of the landscape for the viewer to get a richer experience of the region. Because of this, I reached out to local videographers in and around Darjeeling to augment my footage. I

\footnotetext{
${ }^{23}$ While it is unclear which documentary the workers were specifically referring to at the time, there have been several exposé style films made about the plantations.
} 
collaborated with two: Avinash Kumar, who works for a local video production services company, and Diptendu Dutta, a video journalist. The former was able to shoot some b-roll of specific buildings based on storyboards and descriptions I sent him - for example, the Tea Research Association building and the Planters Club. The latter, Diptendu, had covered the Gorkhaland protests of 2017 and sold me some of his footage. Since the political protests are a pivotal part of my film, this was especially necessary to obtain.

Another way that I filled this perceived gap in my footage was by using footage from the public domain on archive.org. I initially wanted to avoid using any archival footage in this film to challenge myself to rely on only footage that I shot; however, ultimately I considered that this issue has roots with deep historical and colonial significance. Because of this, incorporating historical imagery, particularly of the Himalayas, the Darjeeling railway, and factory process work was useful to show the long-ranging impact of colonization on the landscape.

\subsection{Soundscapes and Landscapes}

The sounds of Darjeeling were inescapable throughout the time I was there, and they added a lot to my own experience of the region. Because it was monsoon season, I heard heavy rainfall often. In Darjeeling, the monsoon season is crucial to the production of the crop, much like the labourers who work in the gardens. The first and second flushes are dependent upon the season, and rain plays an integral role.

The whistle of the infamous train that runs through town is heard regularly throughout the day. This train is intertwined with the history of Darjeeling, as will be explained further on in this paper. In this film, it also acts as a metaphor for the younger generations leaving Darjeeling to 
pursue better opportunities in metropolitan cities. While this generation moves on, Darjeeling remains in a state of political upheaval and ethnic tension and its plantations remain stagnant.

Additionally, the sounds of nature, particularly bird calls, permeate the town and the plantations themselves. During the post-production process, I experimented with different ways to retain and highlight these atmospheric sounds in order to enrich the spectators' filmic experience of the region. For example, while filming Ambika's interview in the forest surrounding her campus, I captured a lot of atmospheric noises of birdcalls, wind blowing, and trees rustling. When editing my footage, I highlighted these sounds by integrating them in various sequences throughout the film. Wherever possible, I raised the audio levels of the atmosphere within interviews as well. There are also sounds from the city centre which complement the nature surrounding the gardens; all of this together forms a vibrant soundscape which one cannot escape while in Darjeeling. While the rain was ultimately too distracting and sounded like white noise, the film's final soundscape aims to complement Darjeeling's landscape by emphasizing the sounds of everyday life.

When it came down to incorporating archival footage, I looked for ways to blend it into more contemporary footage. My initial idea was to use it at the beginning and the end as a framing device in order to suggest a connection between Darjeeling's political past and present. However, upon my supervisor Katy McCormick's advice, I changed the beginning to lead from contemporary into archival footage. Imagery of women walking through the fog, followed by the rolling landscapes of Darjeeling in 2018 transition into the rolling landscape of Darjeeling in the 1930s. This is meant to preserve a sense of mystery around the landscape and present an idea of wanting to clear the fog or confusion around the issues surrounding the area.

Additionally, this project draws upon writing which analyzes the role of "empty" landscapes as embodied spaces for trauma representation. For example, Jessica Neath writes about photographs of Tasmania by Anne Ferran and Ricky Maynard which effectively represent historical trauma 
embedded within empty landscapes. Neath writes that " $[t]$ he materiality of the emptiness is important and particular to the production of history in Tasmania. By documenting these sites, [Ferran and Maynard] show how this production has occurred not only in books or images but also in the land itself." ${ }^{24}$ Drawing inspiration from Neath's analysis, The Tea Workers aims to represent historical traumas and migrations through segments composed of only empty places.

The Tea Workers also draws upon secondary sources such as the aforementioned studies on visual anthropology and ethnography, in addition to research about the relationship between soundscapes and landscapes. For example, there is an inevitable connection between cultural identity and sound. Audio recordings provide valuable insight into the ways that sound can enhance the experience and perceived character of a landscape. ${ }^{25}$ Furthermore, soundscapes provide essential insight into specific spaces and augment one's understanding of the environment through an augmented sensory experience. Ekhehard Pistrick and Cyril Isnart have researched this notion extensively and explain that the ways in which one perceives sound affect the ways in which one views a space, and vice versa. ${ }^{26}$ In their article, "Landscapes, Soundscapes, Mindscapes," they propose that one should consider sounds and spaces as interconnected identities which allow one to experience a situation in a more sensorial way. ${ }^{27}$

This consideration of the acoustic dimensions of a space is particularly relevant to The Tea Workers because the dynamic and multilayered experience of sound is one which mirrors the dynamic visual experience of a landscape. Because the region of Darjeeling is one which has been transitional throughout its history, I aimed to capture audio and visual footage which mirror this

\footnotetext{
24 Jessica Neath, "Empty Lands: Contemporary Art Approaches to Photographing Historical Trauma in Tasmania." Journal of Australian Studies 36 (3) 2012: 309-325.

25 David W Samuels, Louise Meintjes, Ana Maria Ochoa, and Thomas Porcello, "Soundscapes: Toward a Sounded Anthropology." Annual Review of Anthropology 39, no. 1 (2010): 329-45.

26 Eckehard Pistrick and Cyril Isnart, “Landscapes, Soundscapes, Mindscapes: Introduction.” Etnografica, no. Vol. 17 (3) (2013): $503-$ 13.

27 Ibid, 503.
} 
dynamism. Hildegard Westerkamp and her contemporaries' studies on acoustic ecologies informs my approach to composed environments, and The Tea Workers features several such acoustic environments constructed using compositions of various sounds permeating the region surrounding the tea plantations. Additionally, to complement my aforementioned research on visual ethnography, I also draw upon sound ethnography scholars such as Ernst Karel, whose work with the Sensory Ethnography Lab also inform my approach to thinking critically about the creation of acoustic environments.

\subsection{Portraying a Growing Sense of Discontent}

The first two thirds of The Tea Workers establish the relationships between these women, their landscapes, and their work. It explores their thoughts on their past and current wages, on their work and responsibilities as women compared to men, and on how Darjeeling is changing. The purpose of focusing on these themes throughout the first two thirds of the film is to introduce the viewer to the setting and establish a sense of the rhythm of everyday life in Darjeeling. Hints of the protests and shutdown are mentioned by the women near the end of the second third of The Tea Workers, but it is not explicitly explained until later. In this way, the viewer can hopefully confront their own ideals about tea and tourism first, before delving into the deeper underlying political issues in the region.

The last third of the film introduces the more dramatic strikes and shutdown from the summer of 2017. It highlights the essential roles that the women labourers of the tea industry in particular were obliged to play in the protests, while not working during that time. It also presents reflections from some of women who were involved in the protests, as well as their thoughts on the 
aftermath one year later. By introducing this political turmoil later on in the film, the viewer can first empathize with the women in their everyday lives, and then come to understand the additional struggles placed on them by this political upheaval. The unique intersection of struggles that these women face is central to The Tea Workers.

Ultimately, discontent in Darjeeling grows from the fact that in spite of these extreme political moves, and in spite of the women being the faces of these protests, they benefit the least from it because of their status in the hierarchy of the industry. 


\section{Documentary Relevance}

Documentary projects about Darjeeling tend to fall under two opposing categories:

romanticization or exposé. In the former case, the labourers and their work are idealized, along with the landscape of the Himalayan mountains. Throughout my research, I have encountered numerous documentary films and photographic works which romantically portray Darjeeling as a paradise.

For example, contemporary photographer Kelly Doering documented his experiences over the course of three days while working on the Kalej Valley Tea Plantation. ${ }^{28}$ There are several projects similar to Doering's, and most of these represent labourers and the landscape as idyllic and exotic. Another example is photographer Nate Ryan's series, Tea in the Clouds. Ryan begins his artist statement by writing, "[t]here is something about Darjeeling that has a mystical appeal to Americans. As I worked to put together a list of dream places to visit while in India, Darjeeling rose up the list." ${ }^{29}$ There is a tendency, particularly by Western documentarians such as Doering and Ryan, to “nostalgically exoticize" places which have historically been affected by Westernization. ${ }^{30}$ Ethnographic nostalgia has the potential to condescend and idealize at the same time, subsequently leading to an oversimplification of people's experiences and places.

In contrast, some documentary photographers focus on highlighting the hardships faced by plantation workers in the wake of Gorkhaland agitations. Rather than romanticizing the landscape, these projects usually paint a much more negative picture in which the Indian government and owners of large plantations are depicted as taking advantage of labourers. For example, this approach pervades the documentary film Silence Flows, which focuses on a controversy related to

\footnotetext{
${ }^{28}$ Kelly Doering, and Stick People Productions. "Introduction." Stick People Productions / Kelly Doering Documentary Photography / Darjeeling Tea Garden. Accessed April 19, 2018. http://www.stickpeopleproductions.com/p_tea.htm. 29 "India: Darjeeling, Tea in the Clouds." Nate Ryan Photography and Motion. Accessed April 18, 2018. http://nateryan.com/blog/2015/3/4/india-darjeeling-tea-in-the-clouds.

30 Bruce Kapferer, and Dimitrios Theodossopoulos. Against Exoticism: Toward the Transcendence of Relativism and Universalism in Anthropology. New York: Berghahn Books, 2016, 1.
} 
Margaret's Hope Tea Garden. This film is a response to a promotional documentary which portrays the garden as an idyllic paradise. ${ }^{31}$ In contrast, Silence Flows primarily emphasizes the hardships faced by several workers who were fired from Margaret's Hope in 1955, as well as the subsequent struggles that they encountered.

Documentary photographer Vivek Singh documents the ongoing disputes in Darjeeling over the proposed statehood of Gorkhaland. The photographs in his series focus largely on depicting violent scenes of unrest through dramatically framed monochromatic images. Burning fires, raised flags, and determined expressions dominate most of the photographs. The approach adopted by Silence Flows and Singh also oversimplifies both the landscape and the individual experience. Because the subject matter of these documentary projects are so specific, their goals in eliciting certain responses from viewers also sometimes carry political agendas.

Professor Sarah Pink, director of the Digital Ethnography Research Centre in Melbourne, writes that visual ethnography entails more than "a simple process of going to another place or culture, staying there for a period of time, collecting pieces of information and knowledge and then taking them home intact." 32 She suggests that it should involve more than the act of cataloguing or collecting data and that visual ethnographers should strive to represent knowledge based on their own subjective experiences. Within the documentary tradition, there is currently a lack of balanced portrayals of individual experiences among tea plantations in Darjeeling, and I hope to fill part of that gap through a recognition of my own perspective as an outsider being granted temporary access to the community. Positionality within the field of documentary has been written about extensively, and my approach will be informed by the works of scholars such as Ella Shohat, Robert Stam, and Shawn Michelle Smith.

\footnotetext{
31 Activistcanvas. "Silence Flows: The Life in Margaret's Hope Tea Garden, Darjeeling." YouTube. February 23, 2017. Accessed April 19, 2018. https://www.youtube.com/watch?v=do1GPCgYIIM.

32 Sarah Pink, Doing Visual Ethnography. Los Angeles, CA: SAGE, 2013, 22.
} 
Shohat and Stam write about the power structures that exist between a spectator and a subject in "Negotiating Spectatorship," explaining the differences within race, gender, class, sexuality, and ideology which affect the balance. ${ }^{33}$ Smith discusses the politicization of the gaze, as well as the power of challenging the racist or colonial gaze through the act of looking back. ${ }^{34}$ Taking their writing into consideration, I aim to continually remain critical of my own gaze, while prioritizing making space for the voices of women in Darjeeling.

\subsection{Exoticization and the Ethnographic Gaze}

Darjeeling's landscape is largely a product of British colonization. The borders of the hill regions were shaped by British colonizers depending on what the land would be used for. The exoticization of Darjeeling's landscape and tea is related to and a result of this colonial history (cite). When approaching this subject, I aim to challenge further exoticization by avoiding this aforementioned ethnographic nostalgia. By drawing focus to a series of personal recollections, this film hopes to challenge a tendency to oversimplify or generalize the experiences of women working in Darjeeling's tea industry.

In Cross-Cultural Filmmaking: A Handbook for Making Documentary and Ethnographic Films and Videos, Ilisa Barbash and Lucien Castaing-Taylor explain the distinctions between impressionistic, expository, and observational documentary. In the first case, they cite Basil Wright's Song of Ceylon:

[An] impressionistic film ... that experimented with sound was Basil Wright's Song of Ceylon (1934), sponsored by the Ceylon Tea Propaganda Board. The film had a multivocal sound track that articulated a complex and at times ironic counterpoint to the beautiful and

\footnotetext{
33 Ella Shohat and Robert Stam. Unthinking Eurocentrism: Multiculturalism and the Media. Abingdon, OX: Routledge 2014, 350.

34 Shawn Michelle Smith, "Guest Editor's Introduction: Visual Culture and Race." MELUS 39, no. 2 (2014), 1-11.
} 
impressionistic images of Ceylonese life and landscape. The voices that are laid over the images implicitly call the supposed benefits of Westernization into question. ${ }^{35}$

Throughout Wright's film, music can be heard over the narrator and the other voices in the film, resulting in a polyphonic experience of the region. However, Wright's own privilege as a white British filmmaker affects the gaze with which he approaches the subject of tea in the colonized region of Sri Lanka, or Ceylon. While Song of Ceylon includes the voices of locals within the region, the main narration is done by a British male voice. This presents the voice of the British man as the authority on Sinhalese culture. The subjects of the film subsequently become secondary elements which reinforce the ideas and stereotypes of the British male voice. Using this example as a starting point, The Tea Workers aims to steer away from a privileged gaze and instead prioritize the voices of the people living and working in Darjeeling.

When writing about expository documentary, Barbash and Castaing-Taylor explain that "neither the voice-over nor the on-screen commentator necessarily speak in the second person, literally to the spectators, but they both implicitly address an audience, and they both tend to be somewhat set apart from the rest of the film. They seem to comment on the action or the scene, rather than to constitute it or be part of it." ${ }^{36}$

Although The Tea Workers does not include an expository voiceover narration in this style, it does incorporate intertitles at various points throughout the film to explain historical and political conflict. While these intertitles do not explicitly address an audience in the second person, they do imply the existence of an external audience and are removed from the rest of the film. They were necessary because a Western audience would likely not be well-versed in Darjeeling's particular

\footnotetext{
35 Ilisa Barbash and Lucien Taylor, Cross-Cultural Filmmaking: A Handbook for Making Documentary and Ethnographic Films and Videos University of California Press, 1997, 20.

36 Ibid, 20.
} 
history of British colonization. Furthermore, while the Gorkhaland movement gets significant coverage in Indian media outlets, it is not widely covered outside of the Indian subcontinent.

The observational style of documentary, which was a "reaction against both expository and impressionistic styles" 37 and aimed to reflect what was happening in the world with supposedly as little artistry as possible. In spite of a so-called lack of artistry, observational documentaries cannot truly be unaffected by art because filmmaking in itself requires artistry, editing, and the construction of some sort of narrative. Each film has its own "language," which involves making conscious decisions about which camera angles, framing, and movements to use for each shot. Because of this series of choices involved in the production and post-production process, the observational style is not ever a truly neutral reflection of the world.

The Tea Workers incorporates its own film "language" as Barbash and Castaing-Taylor suggest; this includes the aforementioned stylistic decisions in regards to interview subjects, locations, and soundscapes. The film also does not aim to use "a propagandistic hammer" which might be the case with expository documentary. ${ }^{38}$ The Tea Workers aims to pose questions to the audience rather than suggest that any one side of the Gorkhaland movement is right or wrong. The reality is that there is no clear solution which will benefit the labourers, and this ambiguity prevents the film from engaging in propaganda for one side.

Taking all of these different elements of these styles into consideration, it seems that the observational and expository styles are the most prevalent influences in The Tea Workers.

\footnotetext{
${ }^{37}$ Ibid, 21.

38 Ibid, 21.
} 


\subsection{Positionality within the Community}

I was born in Calcutta, which is the capital city of the state of West Bengal. It is also a primarily Bengali-speaking region, in contrast with the primarily Nepali-speaking Darjeeling that is also governed by West Bengal. My family has visited Darjeeling throughout the years as a vacation destination, and my only memory from the one time I'd been there consists of idyllic hills and a long train ride. Part of my reason for pursuing this project was to deconstruct and decolonize my own understanding of Darjeeling's politics and landscape. Throughout this process, I have considered myself an outsider to the community and a lot of my field research has served as learning experience. Through mediators who are insiders, such as my translator and managers within the tea gardens, I have been granted access to a world of complex, multilayered political and cultural conflict, of which I was largely unaware before starting this research. In order to deconstruct the myth of Darjeeling's tea, landscape, and women, it was essential for me to deconstruct my own idealized memories of the place from my childhood.

Chantal Ackerman's De l'Autre Côté features several wide shots of landscapes without any cuts; these scenes go on for several minutes and the events taking place within them remain uninterrupted and at a considerable physical distance. By adopting this technique, Ackerman establishes herself as an outsider looking into the community while still remaining noticeably distanced from its particularities and intricacies. Subsequently, she represents a linear sequence of events without adding much of her own artistry or judgement. When making this film, I hope to represent my own positionality in a similar way through visual techniques.

The Tea Workers also draws inspiration from the way that Gideon Koppel treats the physical landscape in Sleep Furiously. This film provides an intimate, unglamourized look at a farming 
community. Trefeurig is a place which was also the backdrop of political turmoil, as Darjeeling has been for decades; for this reason, Koppel's visual and thematic treatment are useful to consider.

Because of my positionality as an outsider, I chose not to include much of my own voice in the film. However, when I met Ambika and a male activist working in tea plantation labour justice, I was quite interested in learning from their perspectives. They belong to a younger generation, are more educated than the labourers, and do not work in the labour industry. It was interesting to include these perspectives in my research, because the women labourers talked about the younger generations becoming more educated and moving away from Darjeeling to seek better work opportunities and subsequently attain higher class status. It was particularly interesting to balance the women labourers' perspectives with that of Ambika, who is of a younger generation but wants to remain in Darjeeling to help improve conditions on the plantation. This ties into Ambika's own personal connection to Darjeeling's landscape and hopefully provides a balance between perspectives.

\subsection{Sensory Ethnography}

There are several documentary films using elements of sensory ethnography from which I have drawn influence which researching and making The Tea Workers. For example, the films of J.P. Sniadecki provide an interesting point of reference. Foreign Parts is particularly inspiring for the ways that Sniadecki and co-director Verena Paravel use atmospheric sound to intensify the viewer's experience of the landscape. The viewer is forced to reckon with the entire experience and this adds a level of authenticity to the piece. 
The Tea Workers incorporates factory soundscapes, both archival and original, to show the sense of stress and loudness that exists in the everyday work environment for these women. Showing the processes within the factory in between interviews highlights the physicality and the repetition involved in their work. Furthermore, portraying several elements which work together in the factory's ecosystem shows the efficiency involved in the tea production process. One on hand, this highlights the idea that these women are also an essential part of the ecosystem by showing them at work alongside the factory's processes. On the other hand, this also emphasizes their individual experiences through personal reflections in interviews.

The Iron Ministry is also a product of the Sensory Ethnography Lab and provides an immersive look at China's railway system. By offering a varied look and by utilizing a seemingly neutral observational style, Sniadecki provides a unique look at this space. The Tea Workers also draws inspiration from his use of this observational style and the soundscape to create a complex sensory environment.

The railway of Darjeeling is another essential part of its landscape. Originally, there were three T's that supposedly formed the pillars of Darjeeling's economy - tea, tourism, and train. However, in more recent times it changed to tea, tourism, and timber (or teak). ${ }^{39}$ Throughout history, the train has been closely intertwined with Darjeeling's tea and tourism industries. Visitors sometimes ride the train as part of their tour of the gardens. However, the train does not serve much of a purpose for actual travel now; it is mainly a tourist attraction. This hints at another layer of change that is occurring within Darjeeling, and encourages one to question what it means for such an essential part of the landscape to gradually become dissociated with it. The soundscape of Darjeeling always includes the train; it can be heard every hour from anywhere in the city, in spite of

\footnotetext{
${ }^{39}$ Raj Bhattacharya, "Darjeeling Tea." Darjeeling Tourism. Accessed June 2, 2019. https://www.darjeelingtourism.com/darj_0000bb.htm.
} 
its changing status. For this reason, The Tea Workers includes sequences highlighting the train as part of the soundscape and landscape to add to the texture or viewer's understanding of the region.

Manakamana, Stephanie Spray and Pacho Velez's project in collaboration with the Sensory Ethnography Lab, is an experimental film which also features long takes with no cuts. This encourages the viewer to be fully immersed in the atmosphere and dwell on the nuances in its sounds and visuals. The Tea Workers aims to emulate this through an exploration of Darjeeling's soundscape. Furthermore, The Tea Workers draws inspiration from Patrick Shen's In Pursuit of Silence, particularly in the ways that Shen uses the soundscape and the landscape in conjunction with one another. The long scenes and complex sound environments captured in In Pursuit of Silence make the film an immersive and reflective experience.

In her analysis of Sweetgrass, Anna Grimshaw writes, "Barbash and Castaing-Taylor remind us that they will be unhurried as filmmakers, asking their viewers to respect the film's distinctive tempo and to experience its carefully calibrated duration as an integral part of the work itself."40

As is the case with Manakamana, Lucien Castaing-Taylor and Ilisa Barbash's Sweetgrass documents a process with supposedly little interference or artistry. This film was also produced by the Sensory Ethnography Lab and features a heavy emphasis on the soundscape and sensory environment. Drawing inspiration from this, The Tea Workers aims to show several work processes with as little interference or artistry as possible. When filming in the lunch area of Rangaroon's tea garden, I aimed to capture women socializing during their break and speaking freely with one another about their work. I noticed that the women would speak more openly when surrounded by other women who supported their words.

\footnotetext{
40 Anna Grimshaw, "THE BELLWETHER EWE: Recent Developments in Ethnographic Filmmaking and the Aesthetics of Anthropological Inquiry." Cultural Anthropology 26, no. 2 (2011), 247-262.
} 
The Tea Workers also incorporates lots of b-roll with soundscapes from the city centre to show how people exist in the spaces outside of the plantation. It is clear that tea is pervasive throughout the region in spite of the physical distance from the actual plantation. Tea seems to permeate the city as well as its surrounding areas, and I aimed to portray this through long, observational sequences shot in the city.

Anna Grimshaw writes about "the observational moment in ethnographic cinema" which "signaled a significant epistemological, philosophical, and aesthetic shift. It was founded in a new approach to the world that respected its materiality, its continuity, and fundamental ambiguity." ${ }^{\prime}$ Grimshaw suggests that ethnographic cinema began to shift once the observational style of documentary - associated with documentary filmmakers such as Richard Leacock, David Maysles, and Frederick Wiseman - was incorporated, allowing audiences to engage more critically with the subject matter presented.

Darjeeling carried a sense of fundamental ambiguity to me because it was a previously unfamiliar place. For this reason, I wanted to ensure that I approached it in such a way that was respectful of its materiality. I aimed to use an observational eye without much cutting or editing when showing these audiovisual environments.

When writing about his attempts to capture the sensory aspects of hunting culture, filmmaker Lorenzo Ferrarini references the anthropological turn in documentary, as well as its relationship to sensory ethnography:

For more than two decades, visual anthropologists have explored the potential of audiovisual media to represent the sensory dimensions of culture. This exploration has often involved ... the use of audiovisual media to convey sensory dimensions that escape the constraints of language. ${ }^{42}$ [David] MacDougall argues that anthropology does not simply

\footnotetext{
41 Ibid, 247.

42 Paul Stoller, "Beyond Text? Critical Practices and Sensory Anthropology, Edited by Rupert Cox, Andrew Irving, and Christopher Wright. Manchester: Manchester University Press. 2016.” Visual Anthropology Review 32, no. 2 (2016): 200-201.
} 
have a prejudice favoring written text over images, but a tendency to read images and sounds as if they were a kind of language." 43,44

This sums up part of the reasoning behind choosing to explore this subject through a film rather than a photography project; the film allows for a sensory, audiovisual experience of the different regions which make up Darjeeling's environment. It allows for the viewer to travel more dynamically through the gardens, the factories, and the city to witness how tea permeates each of these areas.

According to Fatimah Tobing Rony's essay on Robert Flaherty's Nanook of the North called "Taxidermy and Romantic Ethnography," "[1]ike the time machine of cinema, anthropology as participant observation involve[s] an oscillation between the positions of distance and closeness, subject and object. Anthropology's visualism, its 'ideological bias towards vision,' mean[s] that knowledge [is] 'based upon, and validated by, observation." ${ }^{45}$ However, in films which incorporate a romantic ethnographic lens such as Nanook of the North, there is often an unacknowledged power imbalance between the subject and the filmmaker which has a direct impact on a third-party viewer's experience of a culture. Because “the myth of 'participant observation' was fashioned out of rhetorical devices creating the impression of 'Being There," 46 there is always artistry at play; in reality, it is not possible for the filmmaker to authentically capture the experience of a culture to which he or she is an outsider. Going into this project, I tried to keep this in consideration and accept that this distance must exist.

\footnotetext{
${ }^{43}$ Lorenzo Ferrarini, "Enactive Filmmaking: Rethinking Ethnographic Cinema in the First Person." Visual Anthropology Review 33, no. 2 (2017): 133.

${ }^{44}$ MacDougall, David. The Corporeal Image: Film, Ethnography, and the Senses Princeton University Press, 2006: 1-5.

45 Rony, Fatimah Tobing. The Third Eye: Race, Cinema, and Ethnographic Spectacle Duke University Press, 1996, 313.

46 Ibid, 313.
} 


\section{Conclusion}

Before deciding upon the ultimate structure of The Tea Workers, I was aware of many different threads which are all part of the overarching narrative of Darjeeling: the story of the Gorkhaland uprisings throughout history and how they have affected the region; the story of the changing or unchanging roles of women in the tea industry; the story of British colonization's longlasting impact on the tea industry; the story of labour hierarchies and plantation politics as they relate to racial issues; and the story of how the shutdown during the summer of 2017 relates to land politics. Initially, I was unsure which of these threads to focus on; however, as I continued editing the film, a narrative ultimately began to form which hinted at all of these underlying themes, while still focusing on a more specific story around the changing roles of women in the tea industry.

Throughout the research, pre-production, production, and editing process, I was continually made aware of my own positionality, both as a Canadian filmmaker and as a Bengali-speaking Indian person born in Calcutta. There is a lot of privilege at play in both instances, which puts me at a distance from all of my subjects. This was one of the most difficult things to overcome; however, thinking about this also raised questions from the start about which voices I should prioritize in the narrative rather than my own.

The Tea Workers does not aim to offer any conclusions about the current state of the tea industry. It recognizes that the industry is constantly in flux, and in spite of political uprisings with women tea labourers at the front lines of protests, there is no solution on either side which benefits these women. The industry itself offers no answers, and therefore asks to be questioned.

Word count: 9,664 
Appendix: Project Subjects

1. Meena

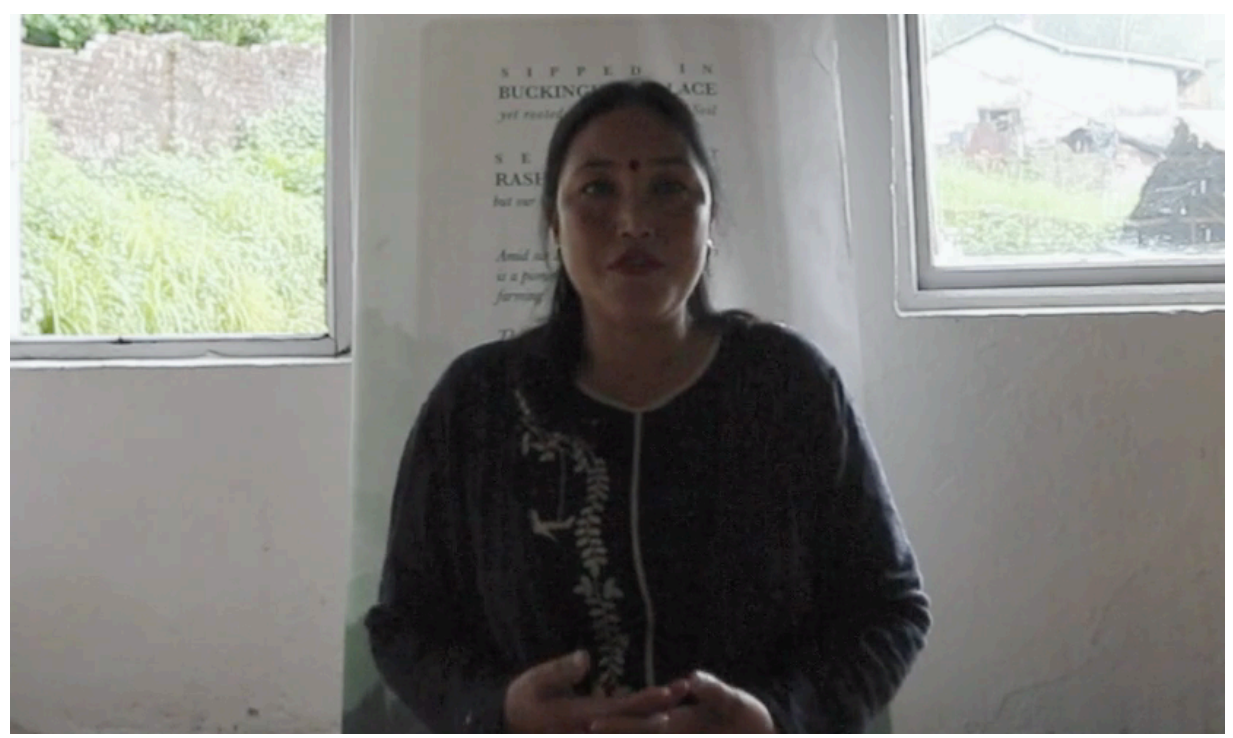

Position: Works in the health department, formerly worked in the gardens

\section{Renuka}

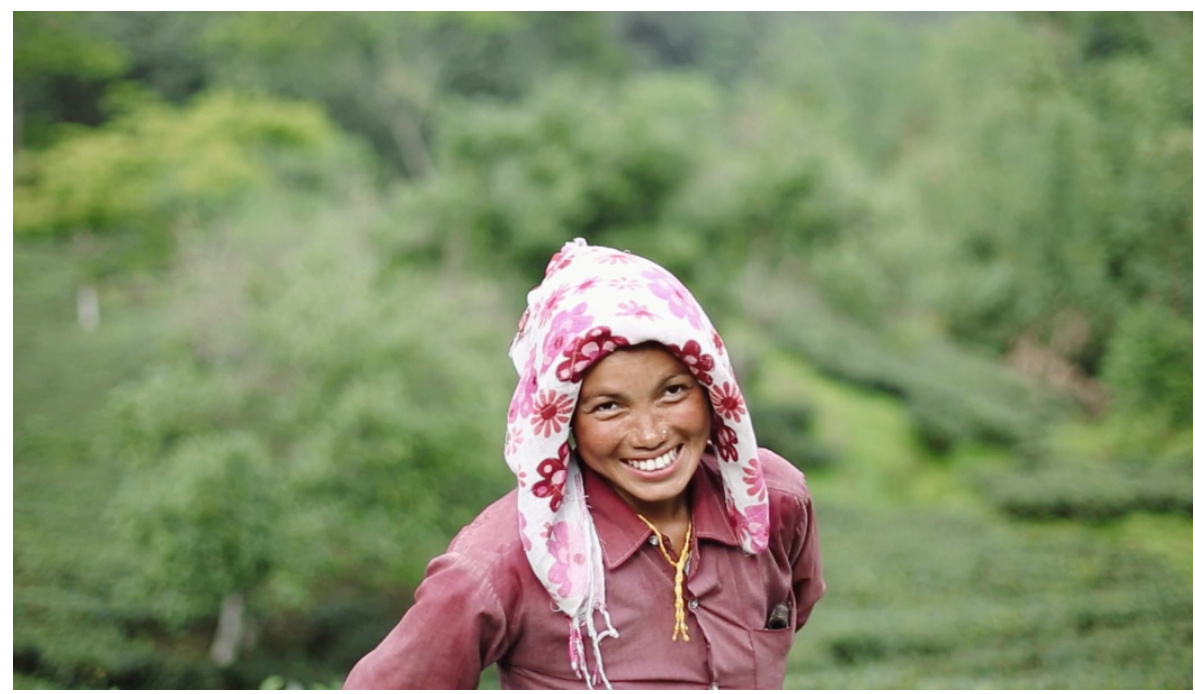

Position: Tea plucker 


\section{Sashi}

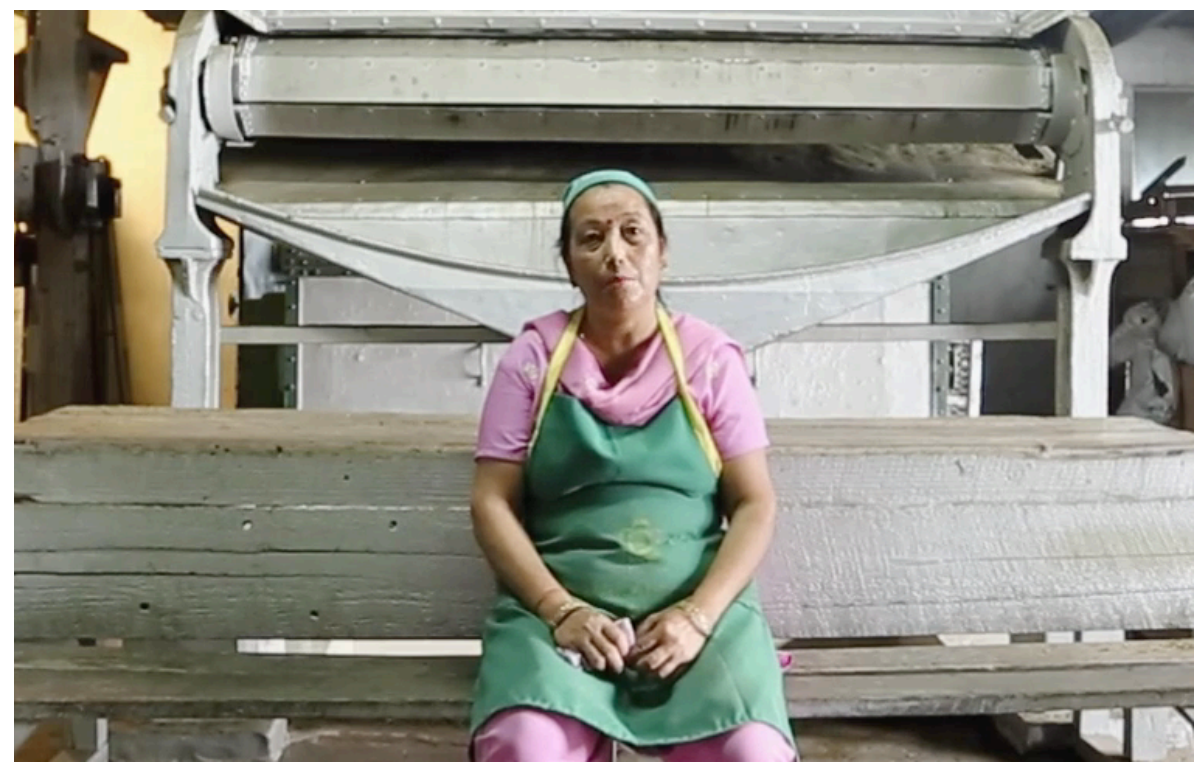

Position: Factory sorting worker

\section{Mandira}

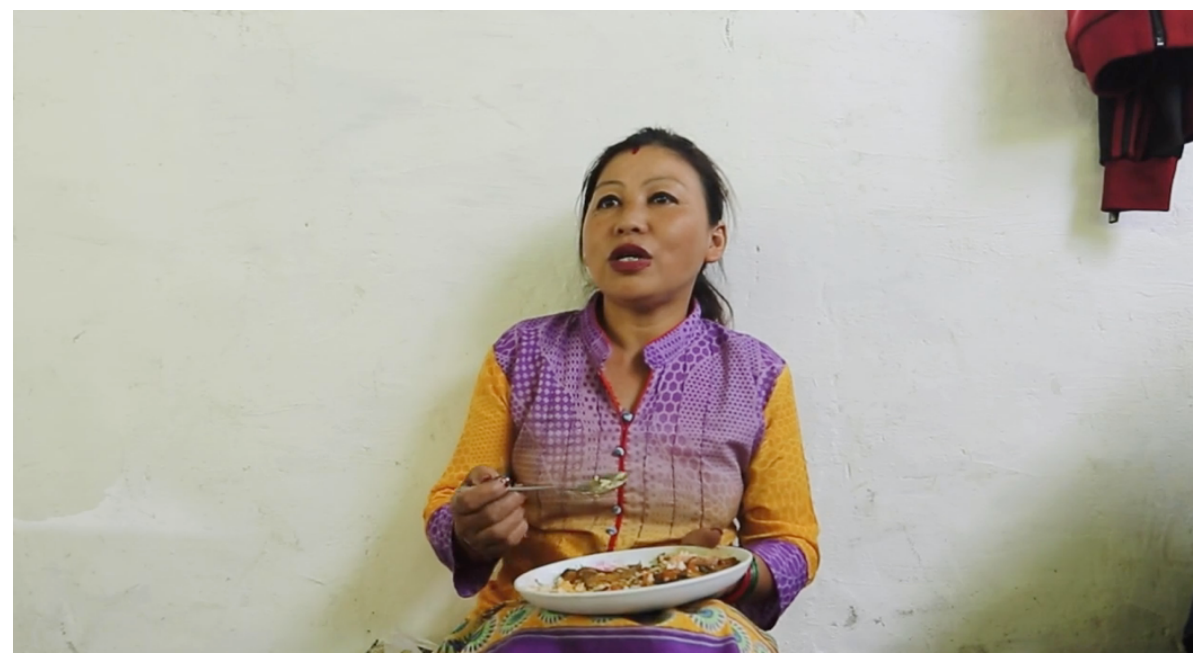

Position: Tea plucker, sorter 
5. Manisha

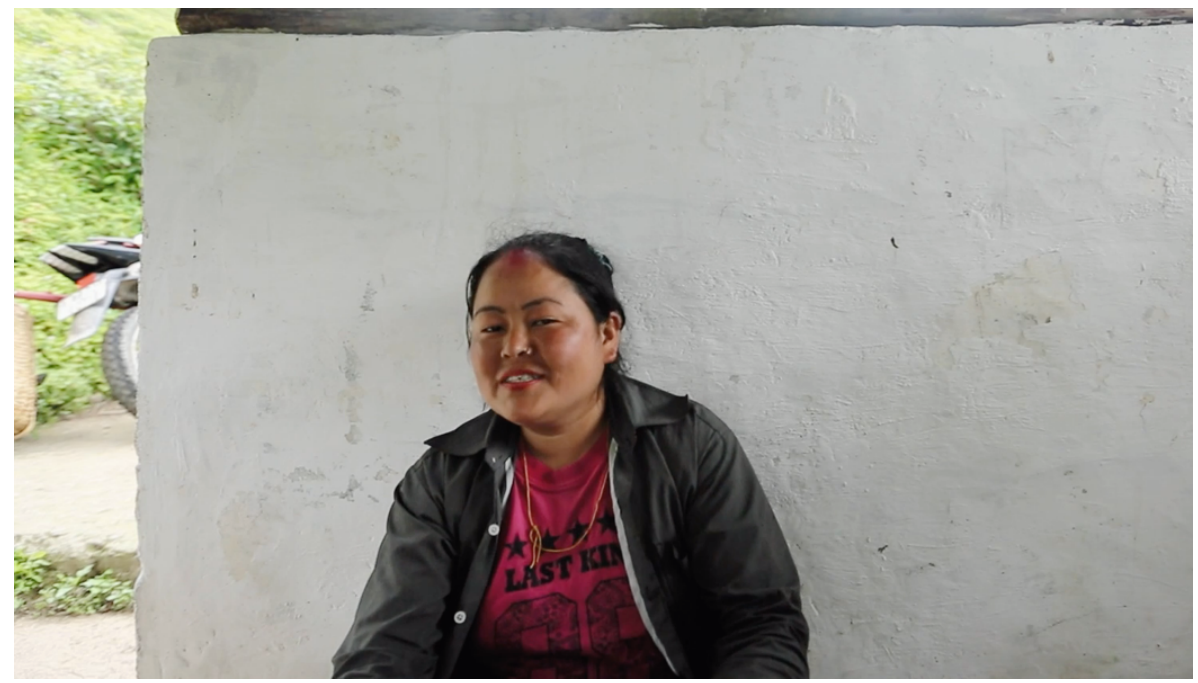

Position: Tea plucker, sorter

\section{Ambika}

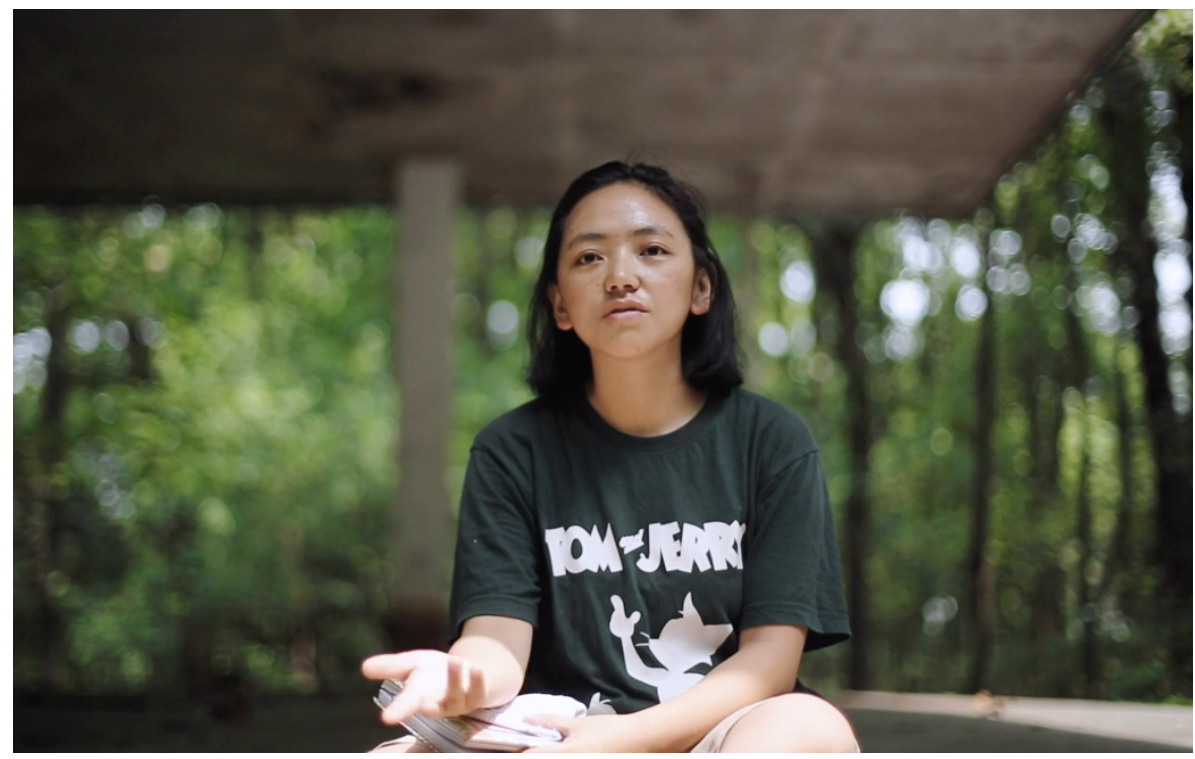

Position: Tea activist, MPhil student at University of North Bengal, specializing in Himalayan Studies 


\section{Bibliography}

Activistcanvas. "Silence Flows: The Life in Margaret's Hope Tea Garden, Darjeeling." YouTube. February 23, 2017. Accessed April 19, 2018. https://www.youtube.com/watch?v=do1GPCgYIIM.

Agnoletti, Mauro. The Conservation of Cultural Landscapes. Wallingford, Oxfordshire, UK: CABI Pub., 2006.

Agrawal, Arun, and K. Sivaramakrishnan. Agrarian Environments: Resources, Representations, and Rule in India. Durham: Duke University Press, 2000.

Anderson, Malcolm. Frontiers: Territory and State Formation in the Modern World. Oxford: Polity Press, 2015.

Bagchi, Romit. Gorkhaland: Crisis of Statehood. New Delhi: Sage Publications India, 2012.

Baker, Michael Brendan. "DRESDEN STORY AND THE EMERGENCE OF THE TALKING HEAD IN THE NFB DOCUMENTARY." Canadian Journal of Film Studies 17, no. 2 (Autumn, 2008): 1-17.

Bandt, Ros. Hearing Places: Sound, Place, Time and Culture. Newcastle upon Tyne: Cambridge Scholars, 2009.

Bandyopadhyay, Sekhar, and Anasua Basu Ray Chaudhury. "Partition in Bengal: Re-visiting the Caste Question, 1946-47.” Studies in History 33, no. 2 (2017): 234-61.

Barbash, Ilisa and Lucien Taylor. Cross-Cultural Filmmaking: A Handbook for Making Documentary and Ethnographic Films and Videos University of California Press, 1997.

Besky, Sarah. The Darjeeling Distinction: Labor and Justice on Fair-Trade Plantations in India. Berkeley: University of California Press, 2014.

Besky, Sarah. "The Land in Gorkhaland: On the Edges of Belonging in Darjeeling, India." Environmental Humanities 9, no. 1 (2017): 18-39.

Bhattacharya, Raj. "Darjeeling Tea." Darjeeling Tourism. Accessed August 17, 2019. https://www.darjeeling-tourism.com/darj_0000bb.htm.

Bhattacharyya-Panda, Nandini. Culture, Heritage, and Identity: The Lepcha and Mangar Communities of Sikekim and Darjeeling. Kolkata: Maulana Abul Kalam Azad Institute of Asian Studies in Association with KW Publishers, New Delhi, 2015.

Bhowmik. Sharit K. "Tea Plantation Wage Agreement: Workers' Interests Sacrificed." Economic and Political Weekly 29, no. 41 (1994): 2645-647.

Blaikie, Piers, and Brookfield Harold. Land Degradation and Society. Norwich and Canberra: Taylor \& 
Francis, 2016.

Booth, Anne. Colonial Legacies: Economic and Social Development in East and Southeast Asia. Hawaii: University of Hawaii Press, 2007.

Chatterjee, Piya. A Time for Tea: Women, Labor, and Postcolonial Politics on an Indian Plantation. Durham (N.C.): Duke University Press, 2005.

Chaudhuri, Sumanta Ray. "Demand for Gorkhaland: How Bengali Language Derailed Peace in Darjeeling." Https:/ /www.hindustantimes.com/. June 15, 2017. Accessed December 14, 2018. https://www.hindustantimes.com/india-news/demand-for-gorkhaland-the-darjeelingcrisis-began-with-the-bengal-govt-announcement/storyS7VdgGSabmfxvLKoXc76mO.html.

Cosgrove, Denis E. Social Formation and Symbolic Landscape. Madison: University of Wisconsin Press, 1998.

“Darjeeling Tea Boutique | About.” Darjeeling Tea Boutique. Accessed March 27, 2018. https://www.darjeelingteaboutique.com/about-us/.

“Darjeeling Tea Estate.” Social Documentary. Accessed April 19, 2018. https://socialdocumentary.net/exhibit/Susan_Kessler/1475.

Davidson, Joyce, and Christine Milligan. "Embodying Emotion Sensing Space: Introducing Emotional Geographies." Social \& Cultural Geography 5, no. 4 (2004): 523-32.

Doering, Kelly, and Stick People Productions. "Introduction." Stick People Productions / Kelly Doering Documentary Photography / Darjeeling Tea Garden. Accessed April 19, 2018. http://www.stickpeopleproductions.com/p_tea.htm.

Donnan, Hastings, and Thomas M. Wilson. Borders: Frontiers of Identity, Nation and State. Oxford: Berg, 2001.

Duncan, J., and N. Duncan. "(Re)reading the Landscape.” Environment and Planning D: Society and Space 6, no. 2 (1988): 117-26.

Feld, Steven. "Places Sensed, Senses Placed: Toward a Sensuous Epistemology of Environments." In Empire of the Senses: The Sensual Culture Reader, 179-92. Oxford and New York: Berg, 2005.

Ferrarini, Lorenzo. "Enactive Filmmaking: Rethinking Ethnographic Cinema in the First Person." Visual Anthropology Review 33, no. 2 (2017): 130-140.

Ganguly-Scrase, Ruchira and Timothy J. Scrase. "Darjeeling Re-made: The Cultural Politics of Charm and Heritage." South Asia: Journal of South Asian Studies 38 (2) 2015: 246-262.

“Garden to Cup: Tea's Illustrious Journey.” DNA India. February 04, 2018. Accessed March 27, 
2018. http://www.dnaindia.com/analysis/column-garden-to-cup-tea-s-illustrious-journey2581220 .

Grimshaw, Anna. "THE BELLWETHER EWE: Recent Developments in Ethnographic Filmmaking and the Aesthetics of Anthropological Inquiry." Cultural Anthropology 26, no. 2 (2011): 247-262.

Hanchey, Jenna N. 2018. "Toward a Relational Politics of Representation." Review of Communication 18 (4): 265-283.

Hung, Po-Yi. Tea Production, Land Use Politics, and Ethnic Minorities: Struggling over Dilemmas on China's Southwest Frontier. New York: Palgrave Macmillan, 2015.

India Darjeeling Strike Ends after 100 Days - BBC News. www.bbc.com/news/world-asia-india41410887.

"India: Darjeeling, Tea in the Clouds." Nate Ryan Photography and Motion. Accessed April 18, 2018. http://nateryan.com/blog/2015/3/4/india-darjeeling-tea-in-the-clouds.

Kapferer, Bruce, and Dimitrios Theodossopoulos. Against Exoticism: Toward the Transcendence of Relativism and Universalism in Anthropology. New York: Berghahn Books, 2016.

"Like Darjeeling Tea? Meet One of the First Women Factory Managers in India's Premier Tea Region.” Pulitzer Center. December 22, 2017. Accessed March 27, 2018. https://pulitzercenter.org/reporting/darjeeling-tea-meet-one-first-women-factorymanagers-indias-premier-tea-region.

Lohia, Sidhartha. "Darjeeling Planters Association.” Wayback Machine. Accessed March 25, 2018. https://web.archive.org/web/20050101090541/http://www.darjeelingtea.com/dpa.htm.

MacDougall, David. The Corporeal Image: Film, Ethnography, and the Senses Princeton University Press, 2006.

“Makaibari Tea Organic Tea.” Makaibari. Accessed March 27, 2018. http://www.makaibari.com/.

Middleton, Townsend. The Demands of Recognition: State Anthropology and Ethnopolitics in Darjeeling. Stanford, CA: Stanford University Press, 2016.

Neath, Jessica. "Empty Lands: Contemporary Art Approaches to Photographing Historical Trauma in Tasmania." Journal of Australian Studies 36 (3) 2012: 309-325.

Nichols, Bill. "The Voice of Documentary." Film Quarterly XXXVI, no. 3 (1983): 17.

Paveck, Hannah. "Creative Criticism: Sound and Listening in Sensory Documentary." Cultural Anthropology. Accessed April 18, 2018. https://culanth.org/fieldsights/1143-creativecriticism-sound-and-listening-in-sensory-documentary. 
Pink, Sarah. Doing Visual Ethnography. Los Angeles, CA: SAGE, 2013.

Pistrick, Eckehard, and Cyril Isnart. "Landscapes, Soundscapes, Mindscapes: Introduction." Etnografica, no. Vol. 17 (3) (2013): 503-13.

Pramanik, Probir. "Meet the 'Gandhian' Women Leading the Gorkhaland Stir in Darjeeling." https://www.hindustantimes.com/. June 20, 2017. https://www.hindustantimes.com/indianews/meet-the-gandhian-women-leading-the-gorkhaland-stir-in-darjeeling/storyraRs8Mvc4H2T7dqcEzmZnO.html.

Pye, Lucian W., and Michael Hutt. “Himalayan Peoples War: Nepals Maoist Rebellion.” Foreign Affairs 84, 2 (2005): 169.

Ramana, P. V. “The Maoist Movement in India.” Defense \& Security Analysis 22 (4) 2006: 435-449.

Rony, Fatimah Tobing. The Third Eye: Race, Cinema, and Ethnographic Spectacle Duke University Press, 1996.

Samuels, David W., Louise Meintjes, Ana Maria Ochoa, and Thomas Porcello. "Soundscapes: Toward a Sounded Anthropology." Annual Review of Anthropology 39, no. 1 (2010): 329-45.

Shohat, Ella, and Robert Stam. (2014). Unthinking Eurocentrism: Multiculturalism and the Media. Abingdon, OX: Routledge. (pp. 347-362).

Singh, Vivek. "Photo Essay: Unrest Intensifies in Darjeeling as Protesters Burn GTA Accord." The Wire. June 29, 2017. Accessed April 20, 2018. https://thewire.in/society/darjeeling-protestgorkhaland-west-bengal.

Smith, Shawn Michelle. "Guest Editor's Introduction: Visual Culture and Race." MELUS 39, no. 2 (2014): 1-11.

Song of Ceylon. Directed by Basil Wright. 1934. https://www.youtube.com/watch?v=LWlxvC-eb-g.

Spradley, James P. The Ethnographic Interview. Australia: Wadsworth Group/Thomson Learning, 1979.

Stoller, Paul. "Beyond Text? Critical Practices and Sensory Anthropology, Edited by Rupert Cox, Andrew Irving, and Christopher Wright. Manchester: Manchester University Press. 2016." Visual Anthropology Review 32, no. 2 (2016): 200-201.

Tagg, John. The Burden of Representation: Essays on Photographies and Histories. University of Minnesota Press, 1993.

Tandon, Suneera. "Darjeeling's Famous Tea Industry Is in Hot Water after Ethnic Conflict Wipes out a Key Harvest.” Quartz. July 07, 2017. Accessed April 19, 2018. https://qz.com/1022629/darjeelings-world-famous-tea-industry-is-in-hot-water-aftergorkhaland-blockade-wipes-out-a-key-harvest/. 
Tea in the Land of Thunder: Field Notes from Darjeeling. April 06, 2016. Accessed March 25, 2018. https://www.youtube.com/watch?v=jqXPGvXkaKQ. 
Filename: Das_MRP_Progress6_091819.docx

Folder: $\quad$ /Users/Prerana/Library/Containers/com.microsoft.Word/Data/Documents

Template: /Users/Prerana/Library/Group Containers/UBF8T346G9.Office/User Content.localized/Templates.localized/Normal.dotm

Title:

Subject:

Author:

Prerana Das

Keywords:

Comments:

Creation Date: 10/2/19 2:09:00 PM

Change Number: 2

Last Saved On: $\quad$ 10/2/19 2:09:00 PM

Last Saved By: Prerana Das

Total Editing Time: $\quad 0$ Minutes

Last Printed On: $\quad$ 10/2/19 2:09:00 PM

As of Last Complete Printing

Number of Pages: $\quad 49$

Number of Words: 11,568 (approx.)

Number of Characters: $\quad 65,938$ (approx.) 